\title{
Migrations in an extreme northern population of Arctic charr Salvelinus alpinus: insights from otolith microchemistry
}

\author{
Richard Radtke $^{1, *}$, Martin Svenning ${ }^{2}$, Daniel Malone ${ }^{1}$, Anders Klementsen $^{2}$, \\ James Ruzicka ${ }^{1}$, Dariusz Fey ${ }^{3}$ \\ ${ }^{1}$ School of Ocean and Earth Science and Technology, University of Hawaii, 2525 Correa Road, Honolulu, Hawaii 96822, USA \\ ${ }^{2}$ Norwegian College of Fishery Science, University of Tromse, N-9037 Tromse, Norway \\ ${ }^{3}$ Department of Oceanography, Sea Fisheries Institute, ul. Kollataja 1, 81-332 Gdynia, Poland
}

\begin{abstract}
Growth and migrations of Arctic charr from a Norwegian Arctic lake system were examined using structural and chemical characteristics of their otoliths as indicators of physiological and habitat characteristics. Measurements of otolith strontium/calcium concentration ratios by wavelength dispersive electron microprobe clearly revealed salinity migrations and provided a life history profile for individual fish. There was wide range in the age at first seaward migration 44 to $13 \mathrm{yr}$; mean $6.7 \mathrm{yr}$ ). $\mathrm{Sr} / \mathrm{Ca}$ concentration data were also used to determine that a few migratory charr occasionally abstained from seasonal migrations. Microchemical techniques are an innovative approach to life history analysis when used in combination with structural analyses of otoliths from migratory fish.
\end{abstract}

KEY WORDS: Strontium. Anadromy Norway Spitsbergen - Electron microprobe - Life history

\section{INTRODUCTION}

Arctic charr Salvelinus alpinus (L.) is an ideal study species for determining how environmental factors affect life history and ultimately population structure and diversity in fishes. Arctic charr have a cosmopolitan distribution throughout the northern hemisphere and are mainly found in rivers, streams and lakes (Grainger 1953, Nyman et al. 1981, Savvaitova 1983, Johnson 1989). Their widespread distribution demonstrates their ability to survive in sub-optimal environments. Their success may be attributed to a plastic phenotype and broad range of life history strategies (landlocked, resident and anadromous).

Determination of the effect of the environment upon phenotype and life history relies upon detailed information about environmental conditions, development rates, growth rates, and mortality during each life histonty stage. At present the available information is limited for charr; however, new techniques are being

•E-mail: radtke@hawaii.edu developed to collect detailed life history information from the microstructure and trace-elemental composition of otoliths (Coutant 1990). The conditions of otolith deposition create daily and seasonal records of age (Beamish \& McFarlane 1983), growth, nutritional history and the hydrographic environment experienced by an individual (Radtke 1984, Radtke \& Shafer 1992).

Strontium ( $\mathrm{Sr}$ ) is one of the most used trace elements in otolith analyses. Sr has the same valence as calcium (Ca) $(+2)$ and a similar ionic radius $(\mathrm{Sr}=0.113 \mathrm{~nm} ; \mathrm{Ca}=$ $0.099 \mathrm{~nm}$ ). Consequently, Sr can interchange with Ca during the deposition processes of aragonitic calcium carbonate upon an otolith's surface (Kinsman \& Holland 1969, Kalish 1989, Gauldie et al. 1991, Radtke \& Shafer 1992). Changes in $\mathrm{Sr} / \mathrm{Ca}$ concentration ratios in otoliths have been related to external environmental factors such as temperature (Radtke 1984, 1989, Radtke \& Targett 1984, Radtke et al. 1990) and salinity (Casselman 1982, Radtke et al. 1988, Kalish 1990, Secor 1992, Reiman et al. 1994) and to internal factors such as somatic growth (Sadovy \& Severin 1992) and gonad development (Kalish 1991). 
The major premise of the present research is that $\mathrm{Sr} / \mathrm{Ca}$ concentration ratios can reveal the movement of anadromous charr between freshwater and seawater. Strontium is found in low concentrations in freshwater (0.07 ppm) compared to seawater ( $8 \mathrm{ppm}$ ) (Angino et al. 1966, Mackenzie \& Garrels 1966, Rosenthal 1981. Bowen 1988). Any movement of individual charr between these 2 environments should be reflected in a change of the Sr/Ca ratio in their otoliths. Time series data of a fish's movement through environments of varying $\mathrm{Sr}$ concentration can be generated by recording the changing Sr concentration in the otolith with increasing distance from the nucleus of deposition. An absolute time frame can be applied to these data by overlaying upon the Sr profile the distance from the otolith's center of each consecutive opaque band (deposited during summer months) and hyaline, or transparent, band (deposited during winter months). When integrated with age histories provided by otolith macrostructure (annuli), concentration profiles act as a recording salinometer providing environmental and migratory histories of individual fish.

We utilize otolith structural and chemical components to study migratory life histories in Arctic charr at the northern limits of their range. The high Arctic ecosystems of Spitsbergen, the largest of the Svalbard Islands (Norway), are special in several ways. Their uniqueness is related to the harsh environment of these extremely northern areas that are at the edge of habitability for freshwater fish. In these northernmost regions, the freshwater habitat is oligotrophic while food is very plentiful in the sea. Yet landlocked, resident and anadromous populations of charr are all found in these freshwater habitats.

Our main objective is to use trace element analysis of otoliths to provide life history data about individual fish. These data will allow us to compare in some detail the life histories of resident and anadromous Arctic charr. Specifically, we will be able to (1) determine whether charr classified as anadromous, based upon their physiognomy (condition factor), demonstrate Sr/Ca profiles consistent with movement between freshwater and seawater; (2) determine the age at which charr recruit to the anadromous population; (3) compare the growth rates associated with resident and anadromous life histories; and (4) determine if and when interruptions of the seasonal migrations among anadromous charr occur. This information will ultimately lead to an understanding of which environmental factors are significant for recruitment into either resident or anadromous populations.

\section{MATERIALS AND METHODS}

Collection of samples. Arctic charr Salvelinus alpinus were caught using electro-fishing, gillnets and traps in August 1990. The sampling location was Lake Varflusjøen on the island of Spitsbergen in Norway located at $79^{\circ} 40^{\prime} \mathrm{N}, 14^{\circ} 20^{\prime} \mathrm{E}$ (Fig. 1). This is an open system with anadromous and resident fish

The group sampled consisted of both anadromous and resident individuals. Fish were weighed to the nearest gram and fork lengths (FL) were measured to the nearest millimeter. FL ranged from 130 to $476 \mathrm{~mm}$ and weight from 15 to $1181 \mathrm{~g}$ (Table 1). Sampling conditions and a detailed description of the lake are given by Svenning (1993). Samples for analysis in this work were selected to cover the complete size range of all available migrant and resident charr.

Fish older than $6 \mathrm{yr}$ and larger than $200 \mathrm{~mm}$ were classified as migratory (anadromous); smaller fish of the same age were classified as resident (Svenning 1993). Migratory fish were distinguished by being heavier and having a higher condition factor than resident fish of the same age. The condition factor of each fish was calculated as the ratio of FL and wet weight (Table 1).

Preparation of otoliths for analysis. In preparation for electron microprobe analyses, sagittae were mounted on 1 inch (ca $2.5 \mathrm{~cm}$ ) diameter glass disks using heat setting petrological epoxy. These samples were then ground using 600 grit grinding paper on the sulcul surface to reveal a sagittal section through the core region (Fig 2). The surface of the specimen to be examined must be extremely smooth or large diffractions of X-rays, and thus analytical errors, result. This

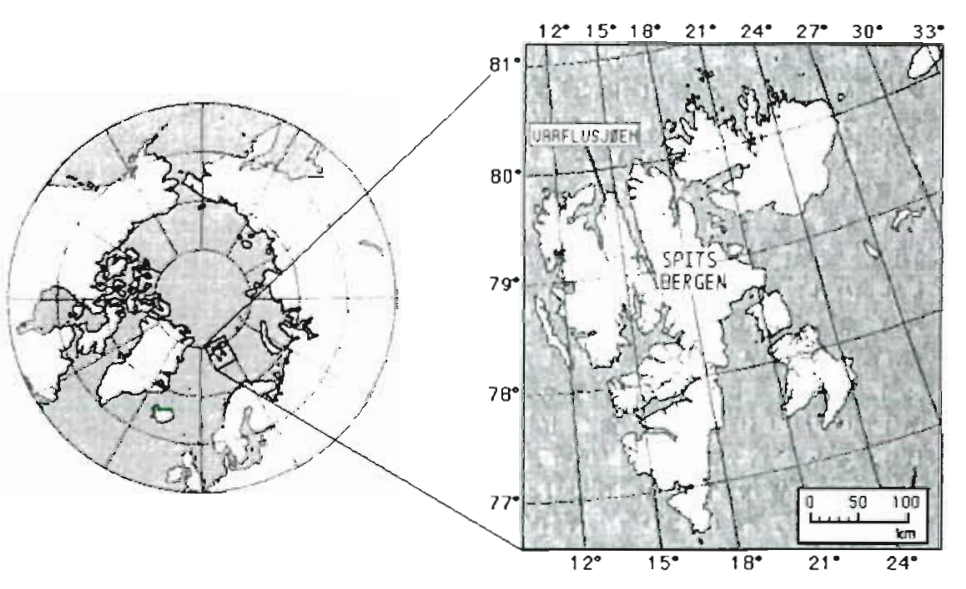

Fig 1 Samples were collected from Lake Varflusjgen on the island of Spitsbergen in the Svalbard Islands, Norway, located at approximately $79^{\circ} 40^{\prime} \mathrm{N}, 14^{\circ} 20^{\prime} \mathrm{E}$. Lake Vårflusjøen covers an area of approximately $1 \mathrm{~km}^{2}$ Samples were collected in August 1990 
Table 1. Sex, fork length, wet weight, condition factor (weight/length), age, age at first migration, and relative growth rates of resident and anadromous Arctic charr Salvelinus alpinus collected from Lake Varflusjøen on the island of Spitsbergen, Norway in August 1990. Age was estimated from sagittal annuli counts. Age at first migration was estimated as the age at which the initial Sr/Ca peak was formed upon the otolith. Relative growth was calculated as $\left[\ln \left(\right.\right.$ length $\left.\left._{0}\right)-\ln \left(l_{\text {ength }}\right)\right] /\left(t_{1}-t_{0}\right)$, where

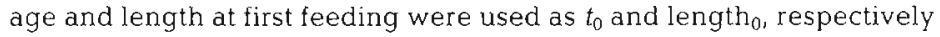

\begin{tabular}{|c|c|c|c|c|c|c|c|c|}
\hline \multirow[t]{2}{*}{ Sample } & \multirow[t]{2}{*}{ Sex } & \multirow{2}{*}{$\begin{array}{l}\text { Length } \\
\text { (mm) }\end{array}$} & \multirow{2}{*}{$\begin{array}{l}\text { Weight } \\
\text { (g) }\end{array}$} & \multirow{2}{*}{$\begin{array}{l}\text { Condition } \\
\text { factor }\end{array}$} & \multirow{2}{*}{$\begin{array}{l}\text { Age } \\
(y r)\end{array}$} & \multirow{2}{*}{$\begin{array}{l}\text { Age at first } \\
\text { migration }\end{array}$} & \multicolumn{2}{|c|}{ Relative growth } \\
\hline & & & & & & & (Over entire life) & (After migration) \\
\hline \multicolumn{9}{|c|}{ Migrant charr } \\
\hline SA 181 & $\mathrm{M}$ & 292 & 292 & 1.0 & 6.5 & - & 0.40 & - \\
\hline SA 203 & $\mathrm{~F}$ & 385 & 705 & 1.8 & 5.5 & 4 & 0.52 & 0.44 \\
\hline SA 205 & $\mathrm{~F}$ & 212 & 88 & 0.4 & 6.5 & - & 0.35 & - \\
\hline SA 221 & $\mathrm{~F}$ & 328 & 378 & 1.2 & 7.5 & 6 & 0.36 & 0.33 \\
\hline SA 233 & $\mathrm{~F}$ & 305 & 363 & 1.2 & 13.5 & 13 & 0.19 & 0.28 \\
\hline SA 242 & $\mathrm{~F}$ & 358 & 622 & 1.7 & 6.5 & 5 & 0.43 & 0.39 \\
\hline SA 243 & $M$ & 415 & 938 & 2.3 & 7.5 & 5 & 0.39 & 0.29 \\
\hline SA 244 & $\mathrm{~F}$ & 415 & 793 & 1.9 & 14.5 & 13 & 0.20 & 0.49 \\
\hline SA 245 & M & 274 & 185 & 0.7 & 7.5 & 7 & 0.34 & 0.63 \\
\hline SA 248 & $\mathrm{~F}$ & 362 & 638 & 1.8 & 6.5 & 4 & 0.43 & 0.24 \\
\hline SA 258 & $M$ & 323 & 439 & 1.4 & 7.5 & 6 & 0.36 & 0.32 \\
\hline SA 313 & $M$ & 374 & 611 & 1.6 & 8.5 & 6 & 0.33 & 0.25 \\
\hline SA 314 & $\mathrm{M}$ & 330 & 438 & 1.3 & 6.5 & 5 & 0.42 & 0.33 \\
\hline SA 318 & $\mathrm{~F}$ & 296 & 297 & 1.0 & 8.5 & 6 & 0.31 & 0.16 \\
\hline SA 330 & $\mathrm{~F}$ & 317 & 319 & 1.0 & 7.5 & 6 & 0.36 & 0.31 \\
\hline SA 335 & M & 387 & 683 & 1.8 & 7.5 & 6 & 0.38 & 0.26 \\
\hline SA 336 & $F$ & 368 & 542 & 1.5 & 11 & 9 & 0.26 & 0.30 \\
\hline SA 340 & $\mathrm{~F}$ & 333 & 398 & 1.2 & 8.5 & 7 & 0.32 & 0.34 \\
\hline SA 341 & $\mathrm{~F}$ & 384 & 697 & 1.8 & 9.5 & 7 & 0.30 & 0.26 \\
\hline SA 344 & $\mathrm{~F}$ & 332 & 424 & 1.3 & 7.5 & 6 & 0.36 & 0.34 \\
\hline SA 345 & M & 362 & 521 & 1.4 & 10.5 & 9 & 0.27 & 0.40 \\
\hline SA 346 & $M$ & 359 & 552 & 1.5 & 7.5 & 6 & 0.37 & 0.39 \\
\hline SA 347 & $F$ & 476 & 1181 & 2.5 & 14.5 & 7 & 0.21 & 0.12 \\
\hline \multicolumn{9}{|c|}{ Resident charr } \\
\hline SA 179 & $M$ & 132 & 16 & 0.1 & 14.5 & - & 0.12 & - \\
\hline SA 183 & M & 153 & 19 & 0.1 & 13 & - & 0.15 & - \\
\hline SA 186 & $\mathrm{~F}$ & 154 & 21 & 0.1 & 14 & - & 0.14 & -- \\
\hline SA 210 & $F$ & 147 & 26 & 0.2 & 7.5 & - & 0.25 & - \\
\hline SA 247 & $\mathrm{~F}$ & 130 & 15 & 0.1 & 14 & - & 0.13 & - \\
\hline SA 269 & $\mathrm{~F}$ & 154 & 28 & 0.2 & 7.5 & - & 0.26 & - \\
\hline
\end{tabular}

surface was highly polished using 0.3 and $0.05 \mu \mathrm{m}$ alumina paste, rinsed with distilled water and ethanol, and given a carbon coating of 25 to $30 \mathrm{~nm}$ thickness to

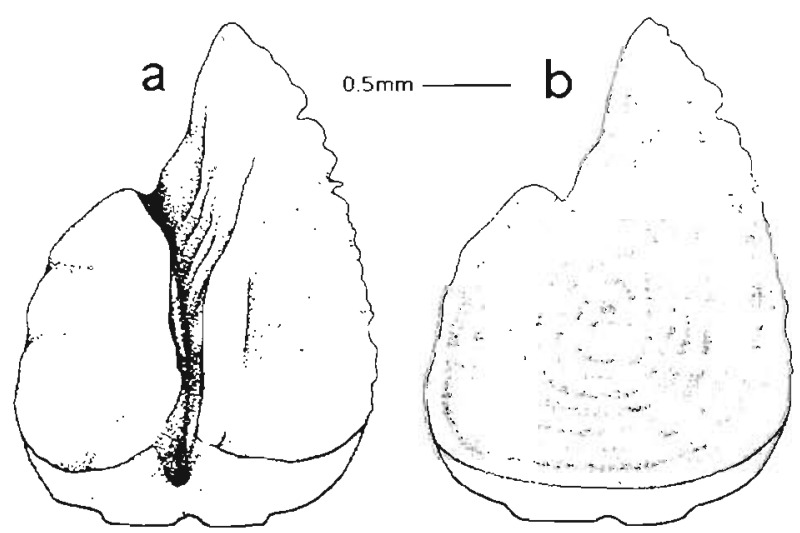

Fig. 2. Drawing of an Arctic charr Salvelinus alpinus sagittal otolith illustrating (a) 3-dimensional shape and (b) internal morphology along the sagittal plane analyzed by microprobe technology conduct charge on the surface of the otolith and to further dampen diffraction of the resultant X-rays.

Analytical conditions. Otolith $\mathrm{Sr}$ and $\mathrm{Ca}$ were measured quantitatively. The samples and standards were analyzed by a Cameca, Camebax SX-50, fixed crystal, X-ray wavelength dispersive electron microprobe (University of Hawaii, USA) using an accelerating voltage of $15 \mathrm{kV}$, a beam current of $8 \mathrm{nA}$, and a $10 \mu \mathrm{m}$ diameter focused beam. Strontianite and calcite were used as standards for calibration of $\mathrm{Sr}$ and $\mathrm{Ca}$ respectively. Characteristic X-rays for $\mathrm{Sr}$ and Ca were counted for $30 \mathrm{~s}$ and background measurements were recorded for $15 \mathrm{~s}$ at each sample location. The crystals used in the X-ray detector were PET for Ca and TAP for Sr. X-ray intensities were corrected and computed using the ZAF method (Reed 1975), and final elemental concentrations were presented as ratios of weight percentage. Relative measurement error percentages were measured according to the equation:

$$
\text { Error }=\left(1 / N+1 / N^{\prime}\right)^{05}
$$



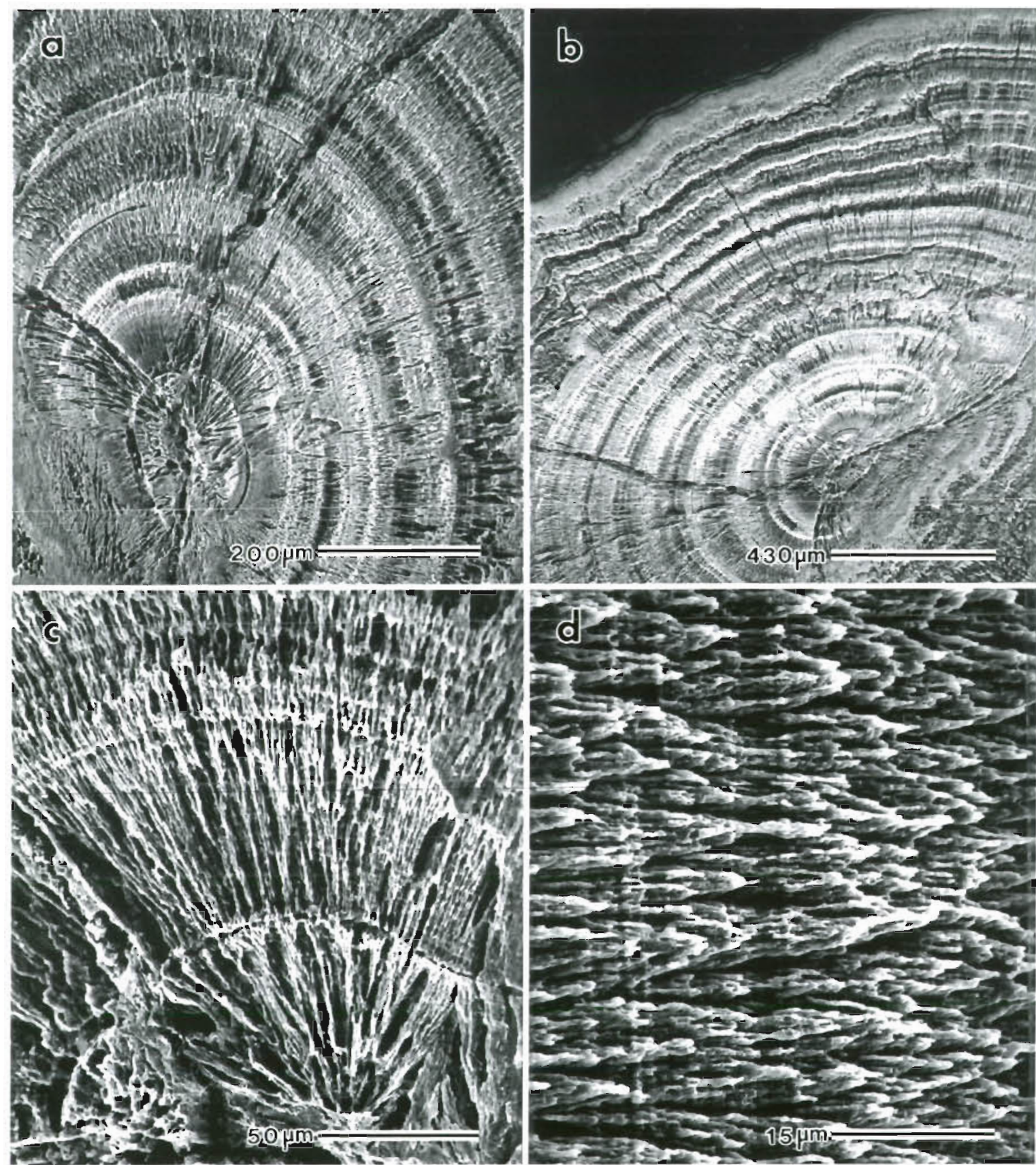

Fig. 3. Scanning electron micrographs (SEM) of sagittal otoliths of Arctic charr Salvelinus alpinus. (a) Sagittal otolith from sample SA 341 showing the central core area, separated by a transitional zone from the outer zone with microincrements radiating outward. (b) The microincrements of SA 341 displayed a range of widths, which were likely related to differences in daly growth rates. As displayed, the microincrements can be discerned despite changes in width. (c) Microincrements from SA 341 found in the first opaque area of the otolith. Using SEM techniques, distinct microincrements were visible in the samples examined. (d) Microincrement patterns from sample SA. 243. Protein ridges and discontınuous zones, comprising microincrements and made visible through EDTA etching, were revealed at high magnifications

where $\mathrm{N}$ is the number of characteristic X-rays counted for an element in the otolith, and $N^{\prime}$ is the number of characteristic $X$-rays counted for an element in the standard (Camebax SX-50 operation manual)
Measurement error values were typically in the range of 4.1 to $4.5 \%$ for $\mathrm{Sr}$ at analysis points considered to represent freshwater residence, and varied between 3.5 and $3.9 \%$ for analysis points with higher Sr con 
centrations that are believed to represent periods of seawater migration. Measurement error for Ca remained consistent at 0.5 to $0.6 \%$.

A series of 200 data points was recorded for each fish along a radius from the core to the margin of the otolith. Scans were usually run from the core to the tip of the rostrum (longest growth axis) except when this area was cracked or had too many surface irregularities in which case a clear path was found to the ventral or posterior margin of the otolith. Sr/Ca concentration ratios were multiplied by $10^{3}$ for presentation.

Correlation of microprobe analyses to otolith structure. After electron microprobe analyses were completed, otolith preparations were cleaned with ethanol to remove the carbon coating. Samples were then examined under a compound microscope at $100 \times$ magnification using transmitted and reflected light to reveal both the annuli and the probe marks left by the electron beam. Images showing these microprobe marks and the annual growth increments (Radtke et al. 1985) were digitized and enhanced using image analysis software. Measurements along the microprobe scan-line from the inner to outer margin of each successive opaque and hyaline zone were taken to the nearest micron. The positions of these structures were then correlated to individual analysis points from the microprobe data. This allowed us to assign ages to individual analysis points and provided us with time series environmental histories of individual fish.

Scanning electron microscopy. After wavelength dispersive electron microprobe analyses, sagittae were cleaned, attached to aluminum stubs and polished. They were etched for 1 or $2 \mathrm{~min}$ in $8 \%$ EDTA (ethylenediamine-tetraacetic acid, $\mathrm{pH}$ adjusted to 8 with $\mathrm{NaOH}$ ) and vacuum-coated with gold for viewing in a scanning electron microscope (SEM) at 1000 to $10000 x$

\section{RESULTS}

\section{Otolith morphology}

The sagittae of Arctic charr are small relative to those of other fish and generally ovoid in shape (Fig. 2), with a rounded rostrum which is larger in bigger individuals (nomenclature from Hecht 1978).

Inspection of Arctic charr sagittae with SEM (Fig. 3) disclosed clearly defined microincrements composed of an unbroken incremental zone with discontinuous zones as boundaries (Radtke \& Dean 1982, MoralesNin 1087). The widths of indiryidual mirrninrrements ranged from 1.5 to $4 \mu \mathrm{m}$, and changes in width were often abrupt. These features are probably due to differences in daily growth rates.

\section{Age estimation}

Within the otolith, annuli are clearly visible. Annuli consist of opaque zones and translucent, or hyaline, zones. As all fish were caught during summer months and the outer edge of each otolith studied was opaque, we conclude that opaque zones were deposited during periods of fast growth in the summer months and hyaline zones were deposited during periods of slow growth in the winter months. The ages of individual fish were determined by counting the hyaline and opaque zones, assuming that each pair corresponded to an annulus (Radtke et al. 1985). From the annuli, the fishes sampled in August 1990 ranged in age from 7 to 16 yr (Table 1 ).

\section{Migrational histories}

Nearly all the individuals thought to be resident charr $(n=6)$, based on condition factors, had low $(<2)$ $\mathrm{Sr} / \mathrm{Ca}$ ratios for the entire time series data set obtained from their otoliths (Fig. 4, Table 2). When the data from migrant charr $(n=23$ ) were analyzed, they demonstrated highly variable $\mathrm{Sr} / \mathrm{Ca}$ concentrations with seasonally repeating regions of high (>2) $\mathrm{Sr} / \mathrm{Ca}$ ratios associated with the opaque zones of their otoliths (Fig. 5, Table 3). These seasonally repeating $\mathrm{Sr} / \mathrm{Ca}$ peaks are interpreted as the chemical signature of the saline marine environment deposited during summer migrations into the sea. Distance measurement errors made with microscopy and the electron microprobe implies that distances measured with these 2 analytical techniques do not have precise 1-to-1 correspondence. Maximum Sr values, therefore, did not necessarily fall within the opaque zone with which the Sr peak is associated. In most cases however, the associated opaque zones contained a large portion of the Sr peak

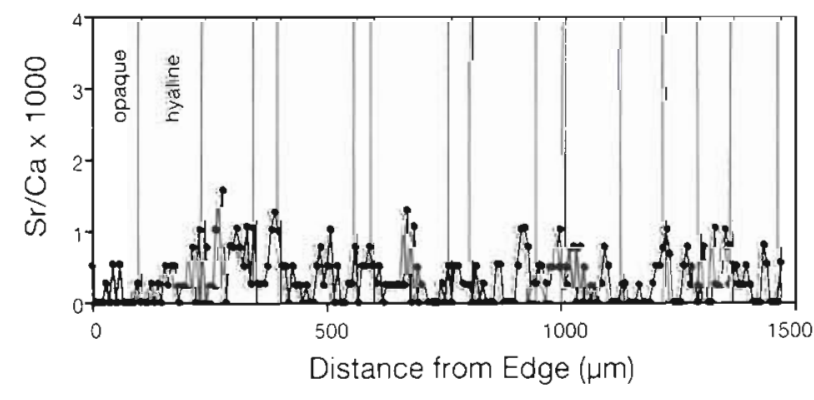

Fig. 4. Microprobe profile of $\mathrm{Sr} / \mathrm{Ca}$ concentration ratios from adult Arctic charr Salvelinus alpınus from Lake Vărflusjøen that displays an $\mathrm{Sr} / \mathrm{Ca}$ ratio that lacked any large peaks above 2.0 that would be indicative of an oceanic foray (SA 210 ). This individual can be classified as resident. All microprobe analyses originated in the central regions close to the core and proceeded outward across the rostral lobe to the edge 
Table 2. Summarized Sr/Ca profiles showing the maximum Sr/Ca ratio within each consecutive hyaline and opaque zone of the otoliths from resident charr Underlined number represents an Sr peak

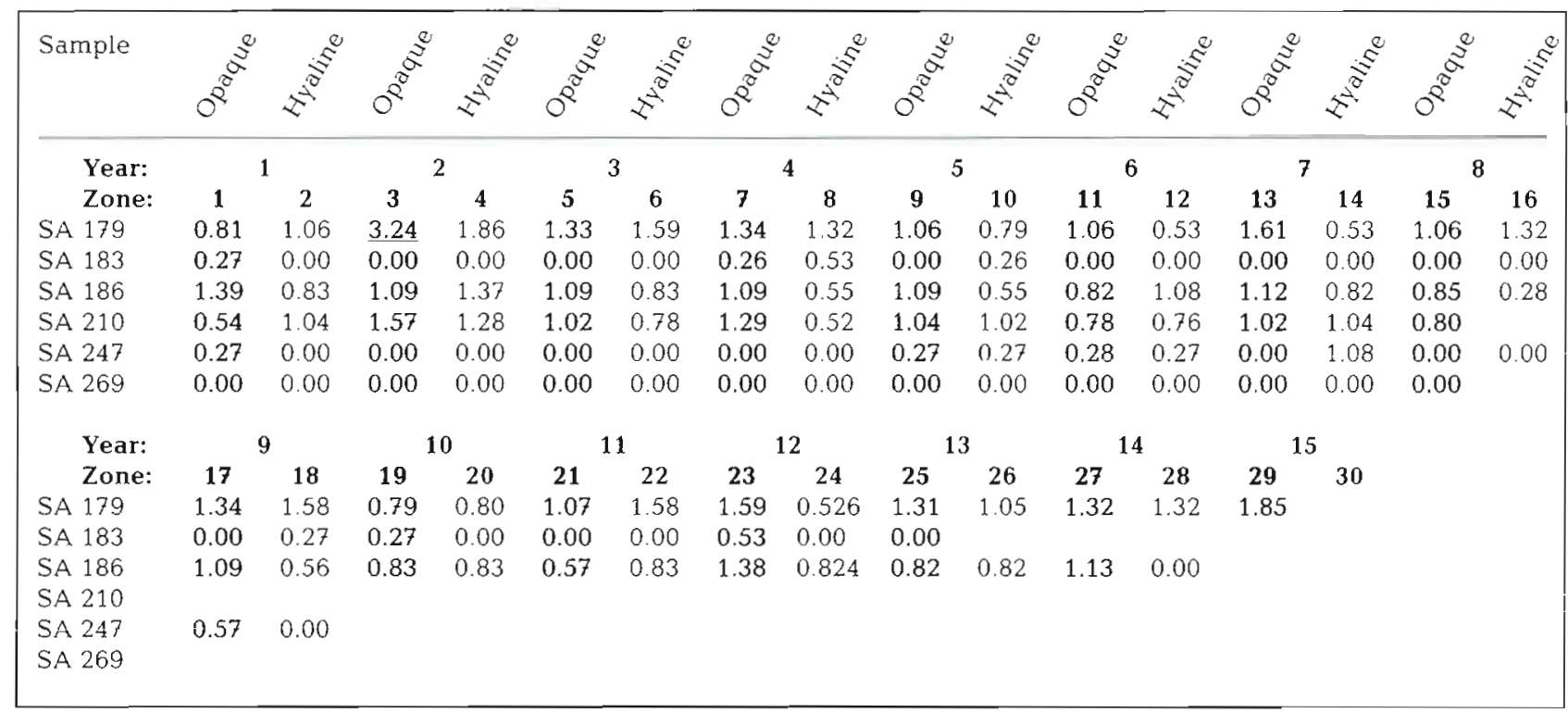

Among the entire group of migratory charr analyzed in this work, the first prominent Sr peak (and therefore we imply the first migration) usually occurred sometime between the 5th and 7th yr. Two samples (SA 203 and SA 248) appear to have begun migration relatively early, in the 4 th yr (Fig. 5b shows SA 203). Four samples (SA 244, SA 233, SA 345 and SA 336) appear to have begun migration late in life, between the 9 th and 13th yr (Fig. 5c shows SA 244). In 3 individuals (SA 347. SA 248 and SA 336), some annual migrations appear to have been skipped altogether or at least are not well reflected in the Sr/Ca profiles (Fig. 5d shows SA 347).

Three anomalous samples need to be noted. First, the resident charr SA 179 demonstrated a single $\mathrm{Sr}$ peak during the 2 nd yr. Perhaps this resident represents a fish that attempted migration during the 2nd yr but failed any subsequent migration. Among migrant charr, SA 181 shows only very weak Sr peaks beginning in the 6th yr. Finally, the presumed migrant SA 205 shows no Sr peaks at all. This individual was originally classified by Svenning (1993) as a migrant based upon its relatively larger size for its age. This fish, however, had an unusually low condition factor for a migrant and had white flesh (Svenning unpubl. data); both conditions are consistent with a resident life history (Svenning 1993). By examining the otolith with the electron microprobe, we were presented with evidence that this individual was likely, in fact, to have been a resident charr, thus again showing the utility of this technique.

\section{Growth}

Relative growth rates (with respect to length) may be calculated by the formula: $r=\left[\ln \left(\right.\right.$ length $\left._{0}\right)-\ln \left(\right.$ length $\left.\left._{1}\right)\right]$ $/\left(t_{1}-t_{0}\right)$. Arctic charr larvae are around $22 \mathrm{~mm}$ long at the time of first feeding (Radtke \& Fey 1996). Using

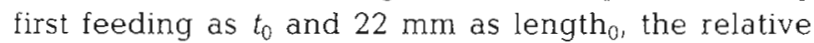
growth rates over the entire life of each fish until capture are calculated (Table 1). Late migrants (SA 244, SA 233, SA 345 and SA 336) have among the slowest growth rates and early migrants (SA 203 and SA 248) have the greatest growth rates.

Svenning et al. (1992) placed anadromous charr between 19 and $23 \mathrm{~cm}$ long when they first begin to migrate. Using a size of $20 \mathrm{~cm}$ as an approximation of the size that charr start migrating, the relative growth rates of each fish after migration are calculated (Table 1). Neither late migrants (SA 244, SA 233, SA 345 and SA 336), early migrants (SA 203 and SA 248), nor those that skipped migrations (SA 347. SA 248 and SA 336) appear unusual with respect to relative growth rate after migration.

\section{DISCUSSION}

\section{Trace element analysis of otoliths}

The Sr content of the otoliths from anadromous fishes has been found to vary in response to freshwater and seawater residence (Casselman 1982, Radtke et al. 1988, Kalish 1990, Secor 1992, Reiman et al. 1994). 

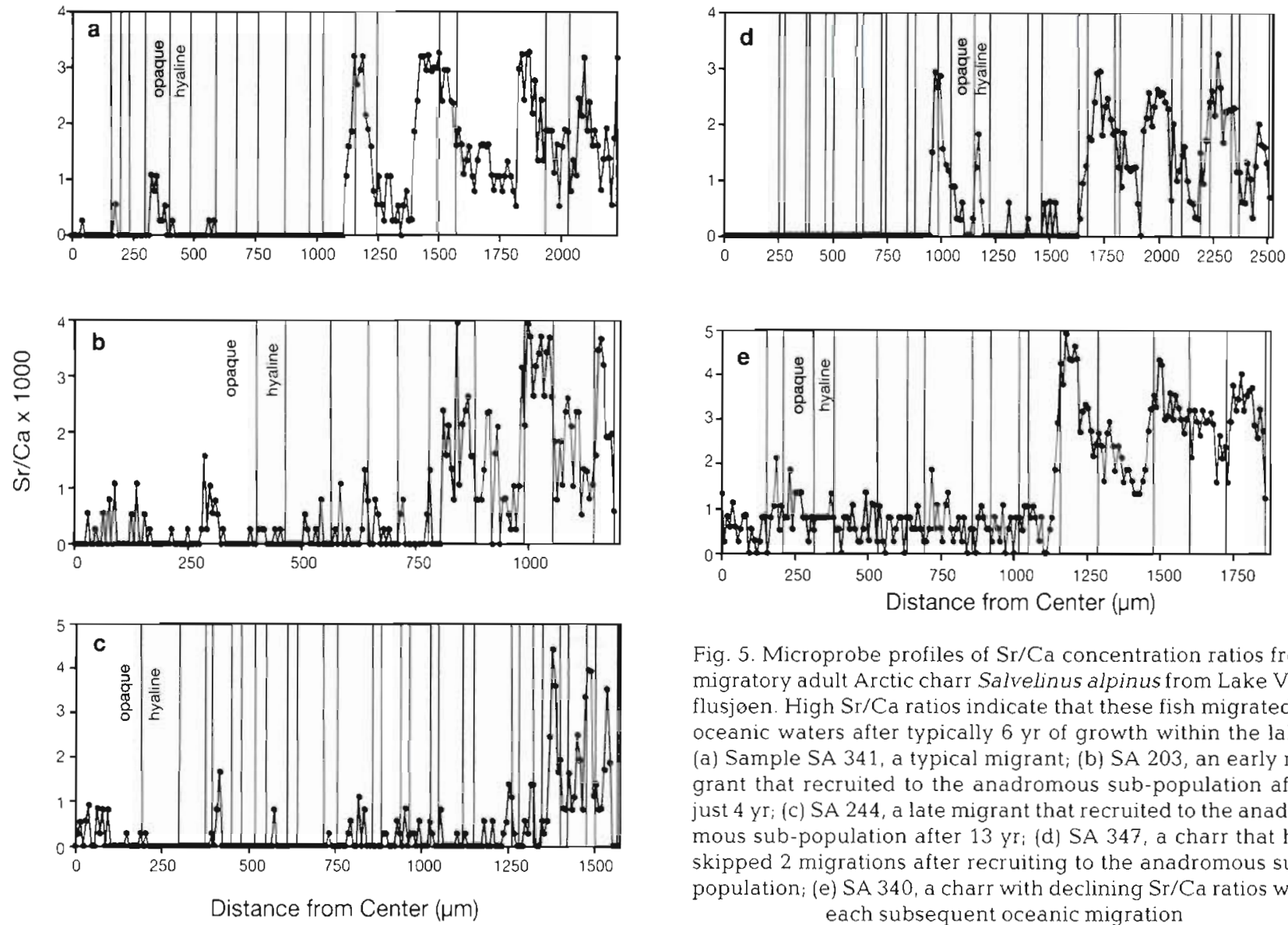

Fig. 5. Microprobe profiles of $\mathrm{Sr} / \mathrm{Ca}$ concentration ratios from migratory adult Arctic charr Salvelinus alpinus from Lake Vårflusjoen. High $\mathrm{S}_{r} / \mathrm{Ca}$ ratios indicate that these fish migrated to oceanic waters after typically 6 yr of growth within the lake. (a) Sample SA 341, a typical migrant; (b) SA 203, an early migrant that recruited to the anadromous sub-population after just 4 yr; (c) SA 244, a late migrant that recruited to the anadromous sub-population after $13 \mathrm{YI}_{i}$ (d) SA 347 , a charr that has skipped 2 migrations after recruiting to the anadromous subpopulation; (e) SA 340, a charr with declining Sr/Ca ratios with each subsequent oceanic migration

Parr-stage Arctic charr reared in freshwater and transferred to seawater for a $3 \mathrm{wk}$ period showed high $\mathrm{Sr}$ concentrations in that portion of the otolith deposited while the fish was in seawater and undetectable $\mathrm{Sr}$ concentrations elsewhere on the otolith (Fig. 6, Radtke unpubl. data\}. Even in inorganic aragonitic carbonate, Sr content is known to be positively correlated with seawater composition (Zeller \& Wang 1956, Oxburgh et al. 1959). The $\mathrm{Sr} / \mathrm{Ca}$ ratio can therefore provide a distinct and unambiguous marker for fishes migrating between higher and lower salinities.

In this study we demonstrate that the $\mathrm{Sr} / \mathrm{Ca}$ content in charr otoliths is correlated with movement between the freshwater and marine environments. The otoliths of migratory individuals revealed distinct cyclic peaks in $\mathrm{Sr}$ content that, when integrated with macrostructural data, could be demonstrated to occur on a seasonal basis. In contrast, the $\mathrm{Sr} / \mathrm{Ca}$ concentration ratio in the otoliths from resident charr remained low $(<2)$ across the entire surface of each otolith; there were no distinct peatss.

Studies similar to this one (but with other species) have demonstrated a change in carbonate chemistry in otoliths and scales that can be correlated to

changes in salinity. Casselman (1982) described a 3fold disparity in the Sr concentration of otolith material deposited during the marine and freshwater life history periods of the eel Anguilla anguilla. Sr concentrations in scales have been used to distinguish freshwater brown trout from sea trout (Bagenal et al. 1973) and anadromous from non-anadromous whitefish (Moreau \& Barbeau 1979). However, the Sr con-

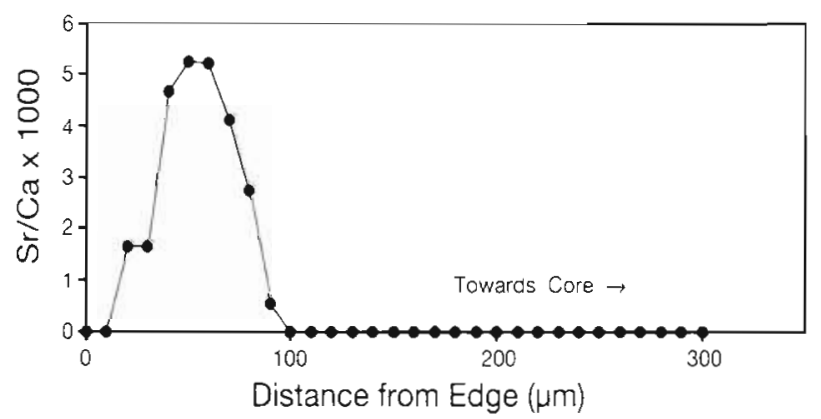

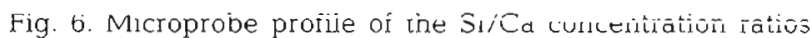
across the otolith of a parr-stage Arctic charr that had been transferred from freshwater to seawater for a $3 \mathrm{wk}$ period and then returned to freshwater 
Table 3. Summarized Sr/Ca profiles showing the maximum Sr/Ca ratio within each consecutive hyaline and opaque zone of the otoliths from anadromous charr This table shows the entre migratory history of individual charr including age at recruttment and migratory or non-migratory status during consecutive summer seasons. Underlined numbers represent each Sr peak For example, charr SA 347 made its first oceanic migration in its 7 th $y \mathrm{r}$ and migrated subsequent summers (except the 8th, 9th, 10th, and 13 th) until its capture at 13 yr of age. Maximum Sr values did not necessarily fall within the opaque zone with which the Sr peak is associated due to the combined distance measurement errors made with microscopy and the electron microprobe. In these instances, < or > symbols point to the probable opaque zone with which the Sr peak is associated

\begin{tabular}{|c|c|c|c|c|c|c|c|c|c|c|c|c|c|c|c|c|}
\hline Sample & 3 & $\approx$ & & 5 & $\Sigma$ & $\approx$ & 3 & $s$ & $\sqrt{3}$ & & 3 & $\approx$ & 2 & 0 & 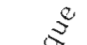 & $s^{e}$ \\
\hline Year: & \multicolumn{2}{|c|}{1} & \multicolumn{2}{|c|}{2} & \multicolumn{2}{|c|}{3} & \multicolumn{2}{|c|}{4} & \multicolumn{2}{|c|}{5} & \multicolumn{2}{|c|}{6} & \multicolumn{2}{|c|}{7} & \multicolumn{2}{|c|}{8} \\
\hline Zone: & 1 & 2 & 3 & 4 & 5 & 6 & 7 & 8 & 9 & 10 & 11 & 12 & 13 & 14 & 15 & 16 \\
\hline SA 181 & 1.12 & 1.37 & 1.10 & 1.10 & 0.83 & 1.09 & 0.55 & 0.00 & 0.28 & 0.28 & 0.82 & 1.67 & 1.84 & & & \\
\hline SA 203 & 1.57 & 0.27 & 0.78 & 1.33 & 0.78 & 0.79 & 3.96 & 3.15 & $\underline{3.94}$ & 2.62 & $\underline{3.67}$ & & & & & \\
\hline SA 205 & 1.34 & 0.79 & 1.05 & 0.53 & 1.34 & 0.78 & $\overline{1.06}$ & 0.52 & 0.53 & 0.53 & 1.07 & 1.05 & 0.00 & & & \\
\hline SA 221 & 2.12 & 0.27 & 1.07 & 1.59 & 1.07 & 1.61 & 1.08 & 0.81 & 0.54 & 1.07 & 4.80 & 3.97 & 4.77 & 3.24 & 3.07 & \\
\hline SA 233 & 1.97 & 1.33 & 1.60 & 0.81 & 0.27 & 0.54 & 0.00 & 0.27 & 0.00 & 0.00 & $\overline{0.00}$ & 0.00 & $\overline{0.00}$ & 0.00 & $\overline{0.00}$ & 0.27 \\
\hline SA 242 & 2.27 & 0.28 & 1.10 & 0.00 & 0.83 & 0.83 & 1.66 & 0.83 & 4.72 & 1.94 & $\underline{3.04}$ & 2.51 & 3.13 & & & \\
\hline SA 243 & 0.89 & 0.00 & 0.00 & 0.00 & 0.00 & 0.00 & 0.00 & 1.97 & $\overline{3.09}$ & 2.51 & 2.80 & $2.00>$ & 0.57 & 0.29 & 1.76 & \\
\hline SA 244 & 0.91 & 0.28 & 0.00 & 0.28 & 1.66 & 0.00 & 0.00 & 0.00 & 0.82 & 0.00 & $\overline{0.00}$ & $\overline{0.28}$ & 1.10 & 0.00 & $\overline{0.56}$ & 0.83 \\
\hline$S A 245$ & 1.15 & 0.27 & 0.26 & 0.52 & 0.52 & 0.00 & 0.26 & 0.52 & 0.79 & 0.26 & 1.31 & 0.79 & 0.79 & $<3.18$ & $\underline{3.56}$ & \\
\hline SA 248 & 0.51 & 0.26 & 0.00 & 0.00 & 0.26 & 0.00 & 3.03 & $<3.84$ & 2.79 & 2.03 & 3.61 & 2.03 & $\underline{3.80}$ & & & \\
\hline SA 258 & 1.11 & 1.10 & 1.38 & 0.55 & 1.37 & 0.83 & 0.27 & $\overline{0.82}$ & $\overline{0.55}$ & 0.83 & 4.96 & 3.27 & $3.5 \underline{3}$ & 2.22 & 4.73 & \\
\hline SA. 313 & & 0.27 & 0.27 & 0.80 & 0.00 & 0.27 & 0.54 & 0.54 & 0.53 & 1.07 & 4.11 & $5.28>$ & 2.44 & 1.89 & 3.82 & 2.87 \\
\hline SA 314 & 1.61 & 0.00 & 1.34 & 0.80 & 0.80 & 0.53 & 0.54 & 0.27 & 4.90 & 4.27 & 4.80 & 2.92 & $\underline{3.50}$ & & & \\
\hline SA 318 & & 1.37 & 0.27 & 0.55 & 1.09 & 1.08 & 1.33 & 1.33 & 1.09 & 5.40 & 6.23 & 4.29 & 5.46 & 2.42 & 4.81 & $6.64>$ \\
\hline SA 330 & 2.20 & 0.55 & 2.73 & 0.00 & 0.55 & 0.55 & 0.55 & 0.28 & 0.00 & 0.27 & 3.62 & $<4.40$ & 4.43 & 3.27 & 5.27 & \\
\hline SA 335 & 1.35 & 0.79 & 0.54 & 0.80 & 0.00 & 0.27 & 0.54 & 0.54 & 0.53 & $3,72>$ & 2.16 & 3.43 & $\overline{3.45}$ & 2.41 & $3 . \overline{95}$ & \\
\hline SA 336 & 0.30 & 0.00 & 0.00 & 0.00 & 0.33 & 0.34 & 0.00 & 0.00 & 0.00 & $\overline{0.00}$ & 0.33 & 0.00 & $\overline{0.00}$ & 0.88 & $\overline{0.87}$ & 1.25 \\
\hline SA 340 & 1.14 & 2.12 & 1.85 & 1.32 & 1.35 & 1.06 & 1.06 & 1.88 & 1.05 & 1.08 & 1.06 & 2.91 & 4.92 & 3.23 & 4.32 & 3.20 \\
\hline SA 341 & 0.27 & 0.55 & 0.00 & 0.00 & 1.08 & 0.27 & 0.27 & 0.00 & 0.00 & 0.00 & 0.00 & 0.00 & $\underline{3.21}$ & 3.21 & 3.22 & $<3.26$ \\
\hline SA 344 & 0.53 & 0.27 & 0.79 & 0.26 & 0.53 & 0.79 & 1.05 & 0.53 & 0.79 & 0.52 & 5.48 & 1.30 & $\overline{3.12}$ & 3.11 & 3.45 & \\
\hline SA 345 & 1.10 & 1.34 & 0.81 & 0.54 & 0.80 & 0.54 & 0.54 & 0.54 & 0.54 & 1.09 & 1.12 & 0.81 & 0.27 & 1.08 & 0.27 & 0.82 \\
\hline SA 346 & 0.55 & 0.53 & 0.00 & 0.27 & 0.27 & 0.27 & 0.00 & 0.00 & 0.00 & 0.00 & 4.08 & 1.63 & -4.39 & 2.70 & $3.46-$ & \\
\hline SA 347 & 0.00 & 0.00 & 0.00 & 0.00 & 0.00 & 0.00 & 0.00 & 0.00 & 0.00 & 0.00 & 0.00 & 0.00 & $\underline{2.92}$ & 2.86 & 0.89 & 1.82 \\
\hline Year: & \multicolumn{2}{|c|}{9} & \multicolumn{2}{|c|}{10} & \multicolumn{2}{|c|}{11} & \multicolumn{2}{|c|}{12} & \multicolumn{2}{|c|}{13} & \multicolumn{2}{|c|}{14} & \multicolumn{2}{|c|}{15} & & \\
\hline Zone: & 17 & 18 & 19 & 20 & 21 & 22 & 23 & 24 & 25 & 26 & 27 & 28 & 29 & 30 & & \\
\hline $\begin{array}{l}\text { SA } 181 \\
\text { SA } 203 \\
\text { SA } 205 \\
\text { SA } 221\end{array}$ & & & & & & & & & & & & & & & & \\
\hline $\begin{array}{l}\text { SA } 233 \\
\text { SA } 242 \\
\text { SA } 243\end{array}$ & 0.00 & 0.27 & 0.00 & 1.07 & 0.80 & 1.07 & 0.80 & 1.07 & $\underline{2.66}$ & 0.82 & 1.10 & $<\underline{3.83}$ & $\underline{3.23}$ & & & \\
\hline SA 244 & 0.56 & 0.28 & 0.82 & 0.28 & 1.37 & 1.10 & 1.38 & 1.38 & 4.41 & 1.94 & 3.35 & $<3.95$ & 3.51 & & & \\
\hline SA 245 & & & & & & & & & & & & & & & & \\
\hline $\begin{array}{l}\text { SA } 248 \\
\text { SA } 258\end{array}$ & & & & & & & & & & & & & & & & \\
\hline SA 258 & 3.72 & & & & & & & & & & & & & & & \\
\hline $\begin{array}{l}\text { SA } 313 \\
\text { SA } 314\end{array}$ & $\underline{3.72}$ & & & & & & & & & & & & & & & \\
\hline $\begin{array}{l}\text { SA } 314 \\
\text { SA } 318\end{array}$ & 4.65 & & & & & & & & & & & & & & & \\
\hline SA 330 & & & & & & & & & & & & & & & & \\
\hline SA 335 & & & & & & & & & & & & & & & & \\
\hline SA 336 & $\underline{3.22}$ & 1.84 & $\underline{3.24}$ & 2.76 & 1.58 & $3.48>$ & & & & & & & & & & \\
\hline $\mathrm{SA} 340$ & $\overline{4.01}$ & & & & & & & & & & & & & & & \\
\hline SA 341 & $\underline{3.28}$ & 1.89 & 3.18 & & & & & & & & & & & & & \\
\hline SA 344 & & & & & & & & & & & & & & & & \\
\hline $\begin{array}{l}\text { SA } 345 \\
\text { SA } 346\end{array}$ & 4.10 & 2.16 & $\underline{4.34}$ & 2.70 & 4.19 & & & & & & & & & & & \\
\hline SA 347 & 0.59 & 0.32 & 0.61 & 1.24 & 2.94 & 1.88 & $\underline{2.62}$ & 2.01 & 1.59 & 2.40 & 3.25 & 2.30 & $\underline{2.00}$ & & & \\
\hline
\end{tabular}

centration in scales was found to be of little use for distinguishing between anadromous and nonanadromous brook charr Salvelinus fontinalis (Castonguay \& Fitzgerald 1982) or between anadromous and non-anadromous Atlantic salmon Salmo salar
(Gausen \& Berg 1988). Mixed results when using scales are not unexpected considering that there is a strong possibility of scale resorption (Bilton 1974) Conversely, otoliths are not easily, if at all, resorbed (Simkiss 1974, Campana 1983). 


\section{Characteristics of migration}

Migratory charr from Spitsbergen appear to move rapidly from freshwater to oceanic waters as revealed by the oscillating Sr/Ca pattern across their otolith surfaces. Trace element analyses of their otoliths suggest that most migratory charr from Spitsbergen first migrate at 5 to $7 \mathrm{yr}$, though there is considerable variation. Studies of populations in Labrador, Canada, suggest that charr first migrate predominantly at 2 to 4 yr (Dempson \& Green 1985). The more northerly charr populations in Spitsbergen appear to begin seaward migrations at an older age than more southerly populations of charr. Such interpretations are possible without expensive and time-consuming tagging research by employing trace element analysis.

Our work and the earlier studies of others indicate that charr make only short duration migrations to the sea. Charr do not generally overwinter at sea (Grainger 1953, Dempson \& Green 1985). This is a behavioral adaptation that prevents freezing in oceanic waters during winter (Craig 1989). Migration to the sea, if it occurs, is often in the spring, and migrants remain in estuarine or coastal waters for 1 to 4 mo before returning to freshwater (Johnson 1980, Power 1980). At Spitsbergen, residence in the ocean is limited to just 6 to $8 \mathrm{wk}$ during the summer (Svenning unpubl. data) and cannot be of longer duration due to diminished stream flow with winter freezing The migration of Arctic charr to sea may be largely for feeding (Gyselman 1984). Consequently, it is possible that their temporal and spatial distribution at sea could be influenced by the distribution of prey organisms.

Arctic charr in Alaska are characterized as 'facultatively anadromous' (Craig 1989). Spitsbergen charr may also be characterized as facultatively anadromous as has been previously suggested by tagging studies (Svenning et al. 1992) and as is demonstrated in the present investigation. Migrant individuals SA 347, SA 248 and SA 336 clearly skipped or had occasional exceedingly brief oceanic migrations. There are 2 hypotheses that could explain why a formerly migrant individual may, for 1 or $2 \mathrm{yr}$, remain with the resident population. Maturing adult Arctic charr may remain in freshwater during the year they spawn, which generally occurs sometime in October or November (Johnson 1980). However, the data are weak to support a migratory 'break' for adults in Lake Vårflusjoen, which is more accessible to the sea than the system described by Johnson (1980). Alternatively, those individuals that skipped migrations were among the less successful predators when at sea and may return to freshwater in non-spawning condition. Consequently, they do not migrate since they lack sufficient energy reserves to migrate or spawn. This could explain the occurrences of non-ripe individuals in returning populations in late August (Grainger 1953, Nordeng 1961).

\section{Growth}

Svenning (1993) has suggested that the early growth rate (Ages $0^{+}$to $4^{+}$) of pre-migratory Lake Varflusjoen charr is greater than those young charr that will remain in the resident population as adults based upon greater annuli widths. We arrived at a similar conclusion based upon size-at-capture and otolith age data. We have also found that early migrants had the greatest growth rates and late migrants had the slowest growth rates of the anadromous fish (Table 1). However, though some migrants such as SA 341 show increased otolith deposition after migration (Fig. 5a), there appears to be no general trend of otolith growth rate (annuli width) increasing after recruitment to the anadromous population. If the same relation between otolith and somatic growth exists before and after charr become migratory, then this implies that (1) there is no increase in growth rate associated with life in the sea and (2) the greater growth rate of the pre-anadromous charr may be a contributing factor toward the option of migrating However, otolith inferences of somatic growth may be suspect for charr (Mosegaard et al. 1988). At present, we cannot distinguish from otolith structure alone whether the greater growth rates associated with migration occur before or after recruitment to the anadromous population

The advantage of greatly increased somatic growth over increased oceanic mortality is probably a major determinant in the option between anadromy and residency (Thorpe 1986, Gross 1987, Metcalfe \& Thorpe 1990). In this study, every large individual was found to present $\mathrm{Sr} / \mathrm{Ca}$ concentration ratios indicative of seawater/freshwater pilgrimages. Migrations are generally into local coastal zones (Craig 1989), where migrants may more than double their body weight (Mathisen \& Berg 1968, Johnson 1989) and experience increased fecundity (Mortensen 1982).

\section{Conclusion}

Fish life history data, including anadromous migration patterns, provide essential information for population dynamics analyses and contribute directly to decision-making in habitat preservation and management. However, despite ambitious studies (Svenning et al. 1992) age and sex specific rates of anadromy remain largely unknown for Arctic charr. Insights from the present investigation still only provide a limited perspective but offer more detail than expansive and expensive tagging studies 
The techniques described in the present study are laborious, but these methods provide a wealth of information, not readily available using other means, that can be obtained retrospectively with archived otolith samples. In actual execution and potential, wavelength dispersive electron microprobe analyses have considerable information to offer aquatic ecology and particularly important management-related questions for anadromous and other migratory fishes. For example, in populations that are facultatively anadromous, the method could measure the proportion of adults that undertake coastal migrations.

Fisheries scientists and managers are hampered by their failure to hone their inferential abilities to a fine art and to take advantage of indirect ways of obtaining useful information or to make inferences from indirect measures. Instead they rely almost entirely on the same techniques practiced for generations (e.g. fish nettingi, and ior repeating population surveys often without reason. In contrast, analysis of the elemental composition of otoliths holds great promise to provide an abundance of inferential information on the migratory and environmental histories experienced by individual fish, including Arctic charr

Acknowledgements. Special thanks are due to R. Kinzie for valuable discussions, S. Lum and $Z$. Wang for untiring help and D. Shafer for reviewing the manuscript. This study was funded by National Science Foundation grants DPP-9123017. OCE-9205936 and DEB-93-22618. This is the School of Ocean and Earth Science and Technology contribution number 4086 and HIGP contribution number 888 .

\section{LITERATURE CITED}

Angino EE, Billings GK, Andersen N (1966) Observed variations in the strontium concentration of sea water Chem Geol 1:145-153

Bagenal TB, Mackereth FJH, Heron J (1973) The distinction between brown trout and sea trout by the strontium content of their scales. J Fish Biol 5:555-55?

Beamish RJ, McFarlane GA (1983) The forgotten requirement for age validation in fisheries biology. Trans Am Fish Soc 112:735-743

Bilton HT (1974) Effects of starvation and feeding on circulus formation on scales of young sockeye salmon of four racial origins, and of one race of young Kokanee, coho and chinook salmon. In: Bagenal TB (ed) Aging of fish. Unwin Bros, London, p 40-70

Bowen R (1988) Isotopes in the earth sciences. Elsevier Applied Science Publishers Ltd, London

Campana SE (1983) Feeding periodicity and the production of daily growth increments in otoliths of steelhead trout (Salmo gairdneri) and starry flounder (Platichthys stellatus). Can J Zool 61:1591-1597

Casselman JM (1982) Chemical analyses of the optically different zones in eel otoliths. In: Loftus KH (ed) Proceedings of the 1980 North American Eel Conference. Ontario Fisheries Technical Report No 4, p 74-82
Castonguay M, Fitzgerald GJ (1982) Critique de la méthode de distinction entre poissons anadromes et dulcicoles de la meme espece par la teneur en strontium de leurs écailles. Can J Fish Aquat Sci 39:1423-1425 [in French, English abstract]

Coutant CC (1990) Microchemical analysis of fish hard parts for reconstructing habitat use: practice and promise. Am Fish Soc Symp 7:574-580

Craig PC (1989) An introduction to anadromous fishes in the Alaskan Arctic. Biol Pap Univ Alsk 24:27-54

Dempson JB, Green JM (1985) Life history of anadromous Arctic charr, Salvelinus alpinus, in the Fraser River, northern Labrador. Can J Zool 63:315-324

Gauldie RW, Coote G, Mulligan KP, West IF, Merrett N (1991) Otoliths of deep water fishes: structure, chemistry and chemically coded life histories. Comp Biochem Physiol 110:1-31

Gausen D. Berg OK (1988) Strontium levels in scales and vertebrae of wild and hatchery-reared Atlantic salmon. Salmo salar L., smolts. Aquacult Fish Mgmt 19:299-304

Grainger EH (1953) On the age, growth, migration, reproductive potential and feeding habits of the Arctic char (Salvelinus alpinus) of Frobisher Bay, Baffin Island. J Fish Res Bd Can 10:326-370

Gross MR (1987) Evolution of diadromy in fishes. Am Fish Soc Symp $1: 14-25$

Gyselman EC (1984) The seasonal movements of anadromous Arctic charr at Nauyuk Lake, Northwest Territories, Canada. In: Johnson L, Burns BL (eds) Biology of the Arctic charr, Proceedings of the International Symposium on Arctic charr, Winnipeg, Manitoba, May 1981 Univ Manitoba Press, Winnipeg, p 575-578

Hecht I (1978) A descriptive systematic study of the otoliths of the Neopterygean marine fishes of South Africa. Trans R Soc S Afr 43:191-197

Johnson L (1980) The Arctic charr, Salvelinus alpinus. In: Balon EK (ed) Charrs: salmonid fishes of the genus Salvelinus. Dr W Junk, The Hague, p 15-98

Johnson L (1989) The anadromous Arctic charr, Salvelinus alpinus, of Nauyuk Lake, N.W.T., Canada. In: Kawanabe $\mathrm{H}$. Noakes DGC, Yamazaki $F$ (eds) Biology of charr and masu salmon. Physiol Ecol Japan, Spec 1:201-227

Kalish JM (1989) Otolith microchemistry: validation of the effects of physiology, age and environment on otolith composition. J Exp Mar Biol Ecol 132:151-178

Kalish JM (1990) Use of otolith microchemistry to distinguish the progeny of sympatric anadromous and non-anadromous salmonids. Fish Bull US 88:657-666

Kalish JM (1991) Determinants of otolith chemistry: seasonal variation in the composition of blood plasma, endolymph and otoliths of bearded rock cod Pseudophycis barbatus. Mar Ecol Prog Ser 74:137-159

Kinsman DJ, Holland HD (1969) The co-precipitation of cations with $\mathrm{CaCO}_{3}$. IV. The co-precipitation of $\mathrm{Sr}^{2+}$ with aragonite between $16^{\circ}$ and $90^{\circ} \mathrm{C}$. Geochim Cosmochim Acta 33:1-17

Mackenzie FT, Garrels RM (1966) Chemical mass balance between rivers and oceans. Am J Sci 264:507-525

Mathisen OA, Berg M (1968) Growth rates of the char, Salvelinus alpinus (L.), in the Vardnes river, Troms, Northern Norway. Rep Inst Freshwat Res (Drottningholn) 48:177-186

Metcalfe NB. Thorpe JE (1990) Determinants of geographical variation in the age of seaward-migrating salmon, Salmo salar. J Anim Ecol 59:135-145

Morales-Nin B (1987) Ultrastructure of the organic and inorganic constituents of the otoliths of the sea bass. In: Sum- 